07;15

\title{
Система контроля точности слежения за Солнцем концентраторных фотоэнергоустановок
}

\author{
() Д.А. Малевский, П.В. Покровский, В.Р. Ларионов, А.В. Малевская, В.М. Андреев \\ Физико-технический институт им. А.Ф. Иоффре РАН, Санкт-Петербург, Россия \\ E-mail: amalevskaya@mail.ioffe.ru
}

Поступило в Редакцию 4 марта 2020 г.

В окончательной редакции 4 марта 2020 г.

Принято к публикации 5 марта 2020г.

\begin{abstract}
Энерговыработка концентраторных фотоэнергоустановок зависит от эффективности концентраторных модулей и точности слежения за Солнцем. Разработана система контроля моментальной точности слежения на основе регистратора и системы проецирования изображения солнечного диска. Выполнен анализ точности ориентации фотоэнергоустановок на Солнце и проведено исследование влияния точности слежения на энерговыработку концентраторных модулей.
\end{abstract}

Ключевые слова: концентраторный фотоэлектрический модуль, система слежения за Солнцем, контроль точности слежения.

DOI: 10.21883/PJTF.2020.11.49490.18273

Возобновляемые источники энергоснабжения являются экологически чистыми и способствуют решению проблем декарбонизации экономики и достижению мировых климатических целей. Солнечная фотоэнергетика становится все более конкурентоспособной, что связано с существенным снижением стоимости солнечных батарей. Так, только в 2018 г. стоимость солнечных фотоэлектрических установок снизилась на $13 \%$ [1]. Согласно глобальной базе данных IRENA [2], значительная часть солнечных фотоэлектрических установок, которые должны быть введены в эксплуатацию в 2020 г., будут обеспечивать меньшую стоимость электроэнергии, чем самые дешевые новые энергосистемы угольной, газовой и дизельной электрогенерации. При этом общая мировая мощность установленных к 2019г. солнечных батарей достигла $509 \mathrm{GW}$, а к 2020 г. - $630 \mathrm{GW}$ (по предварительным оценкам) [2,3].

Дальнейшее снижение стоимости солнечных фотоэнергосистем может быть достигнуто путем увеличения их эффективности. Основной вклад в энерговыработку фотоэлектрических установок, построенных на основе концентраторных фотоэлектрических модулей с каскадными солнечными элементами, вносят КПД модулей и точность слежения фотоэнергоустановок за Солнцем [4]. Рекордные значения КПД каскадных солнечных элементов составляют 47\% при 140-кратном концентрировании (АМ 1.5) [5]. Использование концентраторов солнечного излучения позволяет снизить стоимость фотоэнергосистемы за счет повышения КПД элементов и снижения расхода дорогостоящих полупроводниковых материалов $[4,6]$. Однако применение концентраторных систем требует использования систем слежения за Солнцем, что в свою очередь накладывает определенные требования на точность слежения.
В настоящей работе представлены результаты разработки системы контроля точности слежения за Солнцем и проведены исследования влияния точности слежения на выработку электроэнергии концентраторными фотоэлектрическими модулями.

Разработанная фотоэнергоустановка состоит из восьми концентраторных модулей, расположенных на двухосевом трекере, оснащенном системой слежения за Солнцем [7]. Разработанные и использованные нами фотоэлектрические модули размером $0.5 \times 1 \mathrm{~m}$ состоят

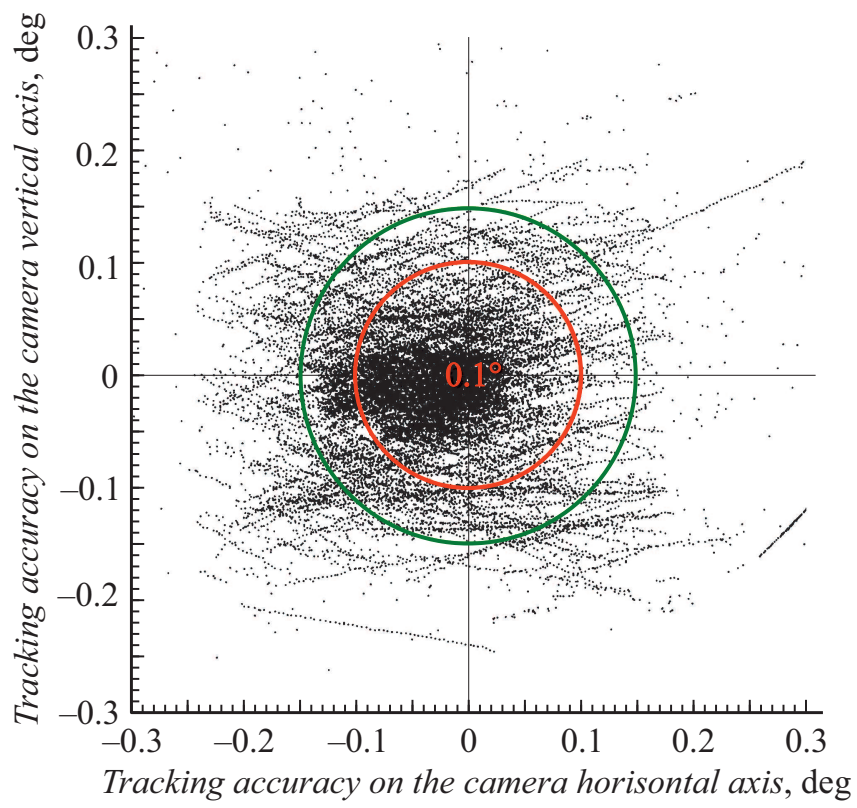

Рис. 1. Оценка моментальной точности слежения за Солнцем по горизонтальной и вертикальной осям видеокамеры, оптическая ось которой установлена перпендикулярно фоточувствительной поверхности концентраторного фотоэлектрического модуля. 


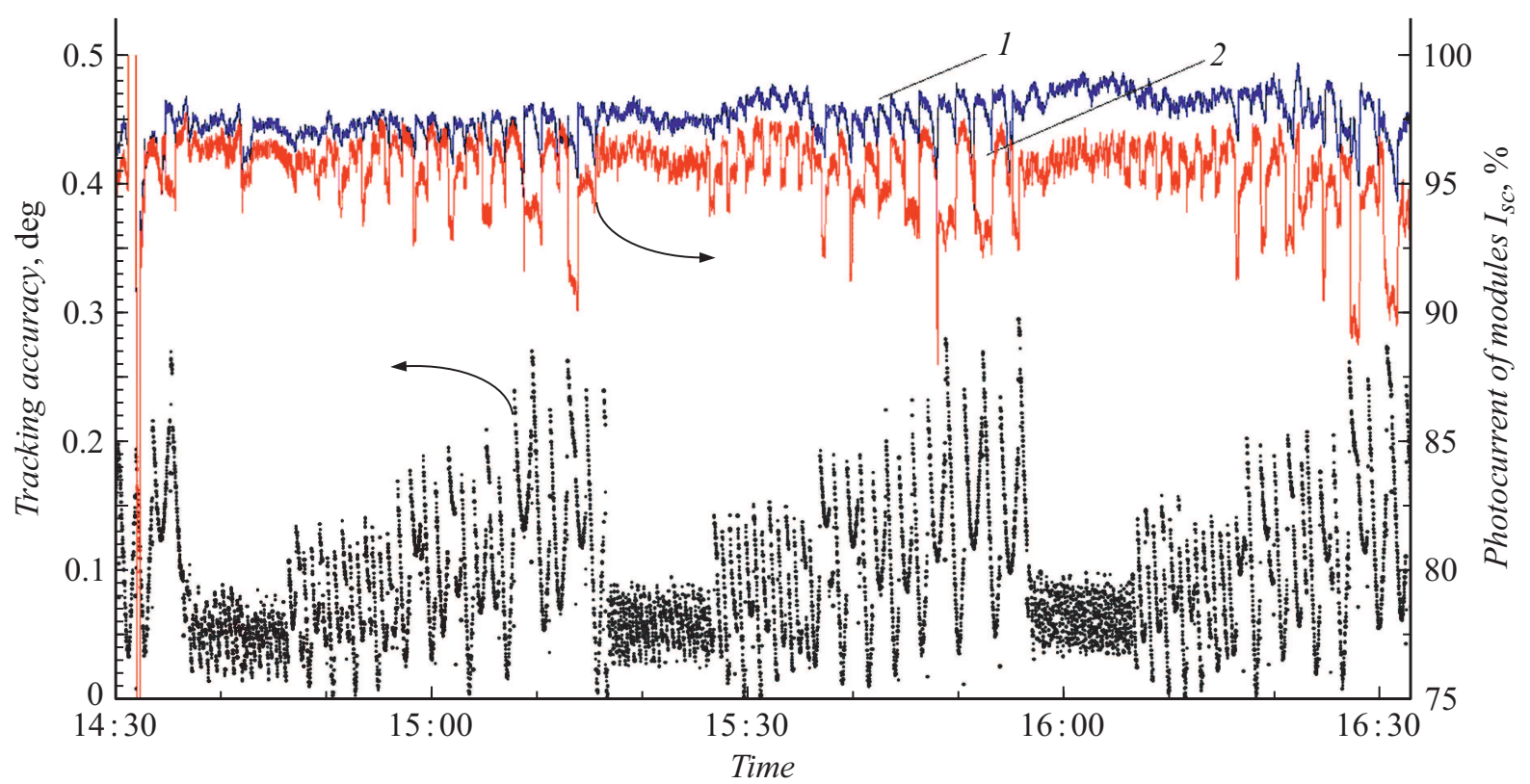

Рис. 2. Временны́е зависимости точности слежения трекера и тока короткого замыкания $\left(I_{s c}\right)$ двух фотоэлектрических модулей $(1$ и 2) в течение периода времени, равного $2 \mathrm{~h}$, демонстрирующие влияние точности слежения на энерговыработку концентраторных модулей.

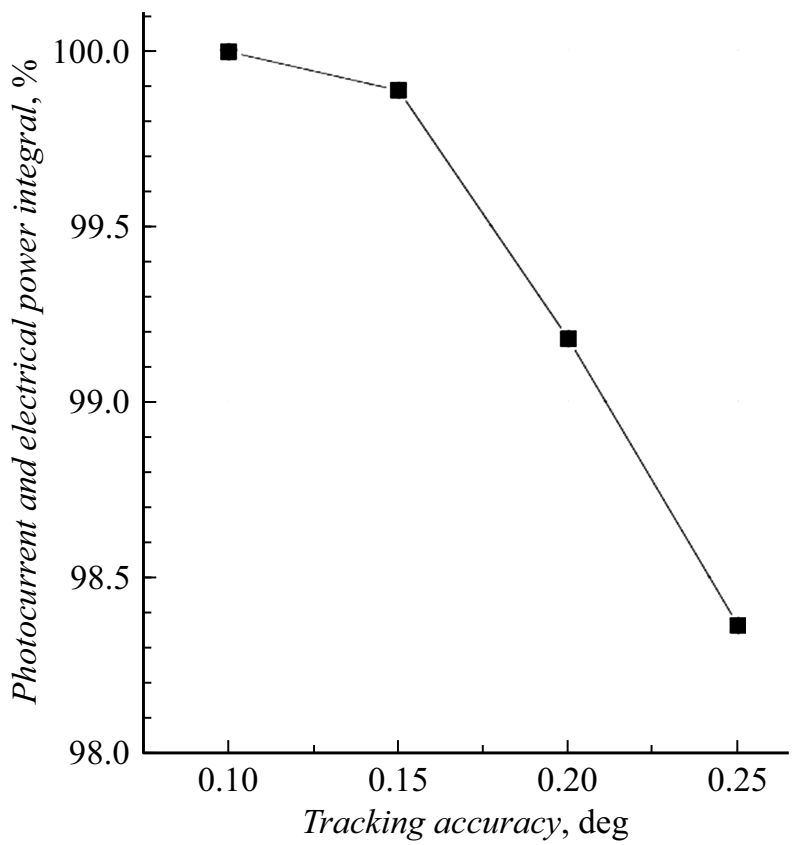

Рис. 3. Зависимость интегральной выработки электроэнергии концентраторным модулем от точности слежения за Солнцем.

из 128 субмодулей, каждый из которых включает линзу Френеля $(6 \times 6 \mathrm{~cm})$ и каскадный солнечный элемент размером $3 \times 3 \mathrm{~mm}$, расположенный в фокусе линзы Френеля.

Ориентация фотоприемной поверхности модулей по нормали к Солнцу осуществляется системой управления трекера по сигналу с фотоэлектрического датчика систе- мы слежения за Солнцем. Датчик состоит из четырех фотоприемников, расположенных за экраном с квадратным отверстием таким образом, что при точном направлении на Солнце каждый элемент освещен одинаково на половину фотоприемной поверхности. Принцип работы датчика основан на сравнении токового сигнала двух противоположных фотоприемников. При нормальном падении солнечного излучения сигнал от фотоприемников одинаков. При изменении угла падения солнечного излучения возникает сигнал разбалансировки между фотоприемниками, и исполнительный механизм трекера выполняет корректировку ориентации. Возможность изменения порогового уровня сигнала разбалансировки, необходимого для начала корректировки ориентации исполнительным механизмом, позволяет регулировать точность слежения за Солнцем.

Для контроля моментальной точности слежения фотоэнергоустановки за Солнцем разработана дополнительная система, состоящая из регистратора - матрицы видеокамеры - и объектива с малой входной апертурой для предотвращения повреждения матрицы концентрированным солнечным излучением.

Для определения моментальной точности слежения проводится анализ изображения, полученного при построении объективом изображения солнечного диска на матрице видеокамеры (рис. 1). По изображению проводится оценка общей освещенности и вычисление „центра масс“ яркостной составляющей. Путем анализа среднего положения „центра масс“ рассчитывается текущее отклонение нормали к поверхности фотоэлектрического модуля от направления на Солнце, что 
является параметром оценки моментальной точности слежения.

Проведено исследование влияния точности слежения фотоэнергоустановки за Солнцем на энерговыработку концентраторных модулей. В ходе проведения эксперимента каждые 10 min изменяется максимальный предел срабатывания датчика слежения за Солнцем, что приводит к изменению точности слежения. Контроль выработки электроэнергии фотоэлектрическим модулем (рис. 2) осуществляется по изменению тока короткого замыкания $\left(I_{s c}\right)$ модуля, который прямо пропорционален мощности модуля.

При максимальном отклонении трекера с модулями от направления на Солнце на $0.1^{\circ}$ изменение $I_{s c}$ не превышает 3\%. При заданном „Принудительном“ снижении точности слежения за Солнцем до $0.25^{\circ}$ уменьшение тока короткого замыкания составляет 8\%, что может трактоваться как моментальное уменьшение мощности модуля на $8 \%$.

На рисунке прослеживаются десятиминутные интервалы (первый интервал от 14:37 до 14:47), в течение которых заданная точность слежения (порядка $0.1^{\circ}$ ) не изменяется. Интегрируя моментальную вырабатываемую мощность за эти периоды времени, можно рассчитать интегральное количество электроэнергии, выработанной модулем. На рис. 3 интегральные значения тока короткого замыкания показаны в процентах от максимального. При этом видно, что, несмотря на достаточно большое изменение моментально вырабатываемой мощности (рис. 2), достигающее $8 \%$ при изменении заданной точности слежения от 0.1 до $0.25^{\circ}$, интегральное количество выработанной электроэнергии снижается менее чем на $2 \%$.

В результате проведенных исследований разработана система контроля точности слежения за Солнцем. Проведен анализ влияния точности слежения на моментальную мощность и выработку электроэнергии концентраторным модулем. Показано, что при изменении заданной точности слежения от 0.1 до $0.25^{\circ}$ моментальная мощность изменяется в пределах 8\%, а суммарная выработка электроэнергии модулем снижается менее чем на $2 \%$.

Разработанная система контроля точности слежения позволяет прогнозировать энерговыработку концентраторных модулей, работающих в составе фотоэлектрических станций с использованием установок слежения за Солнцем различных типов.

\section{Финансирование работы}

Исследование выполнено за счет гранта Российского научного фонда (проект № 17-79-30035).

\section{Конфликт интересов}

Авторы заявляют, что у них нет конфликта интересов.

\section{Список литературы}

[1] IRENA (2019). Renewable power generation costs in 2018. Abu Dhabi: International Renewable Energy Agency (IRENA), 2019. $86 \mathrm{p}$.

[2] IRENA (2019). Renewable energy market analysis: GCC 2019. Abu Dhabi: International Renewable Energy Agency (IRENA), 2019. $153 \mathrm{p}$.

[3] McCrone A. Energy, vehicles, sustainability - 10 predictions for 2020. Bloomberg NEF, 2020.

[4] Concentrator photovoltaics / Eds A. Luque, V. Andreev. Springer Ser. in Optical Sciences. 2007. V. 130. 346 p.

[5] Green M.A., Dunlop E.D., Hohl-Ebinger J., Yoshita M., Kopidakis N., Ho-Baillie A.W.Y. // Progr. Photovol.: Res. Appl. 2019. V. 28. N 1. P. 3-15. DOI: $10.1002 /$ pip.3228

[6] Андреев В.М., Давидюк Н.Ю., Малевский Д.А., Паньчак А.Н., Румянщев В.Д., Садчиков Н.А., Чекалин А.В., Luque A. // ЖТФ. 2014. Т. 84. В. 11. С. 72-79.

[7] Андреев В.М., Румянщев В.Д., Ащеулов Ю.В., Покровский П.В., Чекалин А.В. Патент № 2625604. 17.07.2017. 